\title{
Moral Hazard in High-Risk Environments: Optimal Follow-on Investing in Venture Capital Finance
}

\author{
Julius Tennert $^{1}$, Marie Lambert ${ }^{2}$, and Hans-Peter Burghof ${ }^{3}$ \\ ${ }^{1}$ Corresponding Author. Email: j.tennert@uni-hohenheim.de, University of Hohenheim \\ ${ }^{2}$ HEC Liège, Liège Université \\ 3 University of Hohenheim
}

Venture Capital: an international journal of entrepreneurial finance

Submitted 4th August 2017. Accepted 13th June 2018

\begin{abstract}
This paper examines the joint effect of environmental risk and moral hazard on staging activity in venture capital financing. We show theoretically and empirically that venture capitalists face a trade-off between a) deferring and staging investments to engage in learning of the risky venture and avoid downside losses and b) committing additional funds to update the incentive of the entrepreneur. We describe this trade-off through the timing of follow-on investments and show that highly qualified entrepreneurs demand greater compensation (a larger share) than do less qualified entrepreneurs in situations of high risk.
\end{abstract}

Keywords: Venture Capital; Real Option; Agency Cost; Moral Hazard; Market Risk; Staging; Follow-on investments

JEL classification: G11; G12; G24

\section{Introduction}

Staged financing is a key feature of venture capital financing. The assessment of a business venture is made on the basis of its intangible capital (arising from the business model and the track records of the management team and entrepreneur) and not, in most cases, on a well-detailed business plan. Financial due diligence is limited, and there is the risk of overvaluation. Commonly, venture capitalists (VCs) apply stage financing to control the investment risk and incentivise the entrepreneurs (Amit et al. 1998; Gompers 1995; Sahlman 1990; Wang and Zhou 2014). This gives the VC the option to either abandon the investment in the business or make follow-on investments taking the business to the next milestone. 
However, entrepreneurs operate in highly dynamic markets where future market conditions are uncertain and can change rapidly. For example, technological progress and consumer behaviour can strengthen the firm's business model or completely destroy it. Uncertainty about market conditions cannot be properly controlled by the VC, and it is valuable for the VC to continue to observe market conditions to base his or her investment decisions on higher quality information (Dixit and Pindyck 1994; McDonald and Siegel 1982; Trigeorgis 1996). Hence, staging is valuable for the VC because it allows the option to abandon low-quality firms as well as the option to delay a firm's expansion with respect to market uncertainty.

This flexibility available to the VC impacts the entrepreneur's prospect of capital gain and hence his or her motivation. The entrepreneur will have high motivation to increase their effort to grow their business if market conditions appear favourable and the $\mathrm{VC}$ is willing to provide further investment because these conditions increase the prospect of capital gain. In contrast, the entrepreneur's motivation will decrease if the VC hesitates to provide further investment in the business due to uncertain market prospects because this lowers the prospect of capital gain. In this scenario, consuming private benefits becomes more attractive to the entrepreneur. Our paper is the first to consider the joint effects of agency risk and environmental risk in a dynamic framework. To do so, we model the optimal timing of follow-on investments in a reciprocal problem set, conditional on agency and market risk. We demonstrate that VCs can only capitalise on the full value of the delay option if initial agency risk is low. Delaying the expansion of a business is beneficial if market conditions are uncertain, for example, when the success of a business model is highly conditional on accompanying technological development, but it is less so if the idiosyncratic risk of the firm is highly dependent on the entrepreneur's individual effort, for example, the entrepreneurs human capital. If an entrepreneur's human capital is relevant for the success of the firm, the VC must increase the entrepreneur's incentive for effort to a greater extent in a more risky environment than in a less risky one. As a consequence, the $\mathrm{VC}$ faces a trade-off between deferring investments to avoid the risk of downside losses and committing additional funds to increase the incentive of the entrepreneur. We examine this trade-off through the timing of follow-on investments.

To analyse the funding decision of the $\mathrm{VC}$ in a real-options framework, the following two assumptions must be met (Hsu 2010; Li 2008). The first assumption is that market risk is exogenous to organisational activity, which means that it cannot be impacted by the VC or the entrepreneur. We assume that market risk is related to unexpected market developments, e.g., technological shocks, trending consumer behaviour or competitors' responses that impact the value of the entrepreneurial business; however, it is out of the control of the VC and the entrepreneur and resolves primarily with the passage of time (Dixit and Pindyck 1994; Li 2008; McGrath 1997; Pindyck 1993). The second assumption is that agency risk is endogenous to organisational activity. Agency costs in entrepreneurial ventures are related to the relationship between the VC and the entrepreneur. The entrepreneur is a contracting agent and owns unique human capital, such as specific skills or knowledge, which are essential to the venture's success. We assume that this provides the entrepreneur with power to threaten the $\mathrm{VC}$ with hold-up because the $\mathrm{VC}$ cannot continue to run the 
business without the entrepreneur (Neher 1999). Note that the VC can incentivise the entrepreneur to continue the venture and realise the venture through organisational activity such as contingent control allocation (Chan et al. 1990; Kirilenko 2001) and the use of convertible securities (Casamatta 2003; Cornelli and Yosha 2003; Repullo and Suarez 2004; Schmidt 2003). A more direct incentive is the entrepreneur's prospect of capital gain from his or her share in the business. In this paper, we demonstrate how the entrepreneur's prospect of capital gain from his or her share in the business changes in high-risk environments. As a result, our study has implications for theory and practice. To date, papers have considered agency conflicts in business ventures to be time invariant (Bergemann and Hege 1998; Neher 1999; Cornelli and Yosha 2003). We show that this assumption is not realistic since the strength of agency conflicts is related to the entrepreneur's prospect of capital gain and hence is influenced by market factors and varies over time. We address one of these market factors, namely, market uncertainty.

The remainder of this paper is structured as follows. In section 2, we introduce a formal model to demonstrate the interdependence of market risk and agency risk and their impact on the timing of follow-on investment. In section 3, we test the implications from the formal model empirically. Section 4 concludes.

\section{Formal Model}

\subsection{The Entrepreneurial Venture}

Financially constrained entrepreneur $E$ initiates a business with uncertain returns in $t=0$. $E$ must provide effort $\varepsilon$ to run the business, with $\varepsilon=\{0,1\}$. The business can be expanded by a follow-on investment. The funds are provided by non-constrained venture capitalist $V C$. The effort of the entrepreneur is a critical resource for the business' success; the $V C$ cannot run the business without the human capital of the entrepreneur (Hart \& Moore, 1994). We describe the expansion of the business as a one-shot problem. This assumption implies that the expanded business cannot be shrunk any further.

The $V C$ and the $E$ are considered to be risk-neutral. The $V C$ provides the total investment in equity financing. The business requires an investment $\mathrm{K}$ to be expanded. Investments are sunk once they are committed to the business. Time is standardised to the interval $[0 ; 1]$. The discount rate is $d=0$. The $V C$ decides about the expansion at time $T$, with $0 \leq T \leq 1$. At that time, the $V C$ and $E$ (re-)negotiate a sharing contract. The sharing contract defines the $E$ 's share $S_{E}$ of the business' payoff.

In $t=1$, a stochastic market shock $\pi$ is realised with probability $(1-p)$, with $p \in[0,1] .(1-p)$ is ex ante known by the $V C$ and the $E$. If the market shock is being realised in $t=1$, the business fails and is valueless. Otherwise, the business generates the payoff $V(\varepsilon)$. The business value follows a Bernoulli distribution.

$$
V(\varepsilon)=\left\{\begin{array}{cl}
0 & w \cdot \operatorname{Pr} \cdot(1-p) \\
V(\varepsilon) & w \cdot \operatorname{Pr} \cdot p
\end{array}\right.
$$


with $V(1)>0$ and $V(0)=0$. The sequence of events is illustrated in Figure 1.

\section{[INSERT FIGURE 1 HERE]}

\subsection{Maximisation Function of the VC}

The market risk $(1-p)$ constrains the business' expected payoff. The probability $(1-p)$ is out of the control of the $V C$ and the $E$ and decays with the passage of time. There is a confidence level $\theta_{\pi}(T)$ at time $T$ to update (1-p) over time. It describes the aggregation of beliefs. $\theta_{\pi}(T)$ is based on the square-root-of-time rule. The rule allows to scale down a higher frequency risk estimate to a lower frequency risk estimate. It is commonly used when financial risk is time aggregated. The confidence level $\theta_{\pi}(T)$ is

$$
\theta_{\pi}(T)=T^{0.5}
$$

$P(0)^{V C}$ describes the case where the $V C$ immediately invests $K$ in $t=0$. In this case, the $V C$ immediately expands the business, and the negotiation about the entrepreneur's share $S_{E}$ occurs in $t=0$. The $V C^{\prime} S$ expected payoff $P(0)^{V C}$ is

$$
P(0)^{V C}=-\mathrm{K}+\left(1-S_{E}\right) p V(\varepsilon)
$$

Over time, the $V C$ becomes more confident about the probability of shock $\pi$ being realised in $t=1$. $P(1)^{V C}$ describes the case where the $V C$ invests $K$ in $t=1$. In this case, the $V C$ capitalises on the delay option. The follow-on investment is delayed until uncertainty about the realisation of the shock is disclosed. The expected payoff of the $V C$ still depends on $p$ because the $V C$ expands the business in $t=1$ only if the shock is not realised. We assume that the $V C$ cannot expand the business later than $t=1$. For $t>1$, the investment opportunity vanishes. The expected payoff $P(1)^{V C}$ is

$$
P(1)^{V C}=\left(-\mathrm{K}+\left(1-S_{E}\right) V(\varepsilon)\right) p
$$

The economic value of delay option $D(T)$ is positively related to probability $(1-p)$ and delay $T>0$.

$$
\begin{aligned}
& D(T)=P(T)^{V C}-P(0)^{V C} \\
& =\theta_{\pi}(T)[-\mathrm{K}(p-1)]
\end{aligned}
$$


The expected payoff $P(T)^{V C}$ is

$$
P(T)^{V C}=-\mathrm{K}+\left(1-S_{E}\right) p V(\varepsilon)+\theta_{\pi}(T)[-\mathrm{K}(p-1)]
$$

\subsection{Participation Constraint of the Entrepreneur}

$E$ chooses between the two effort levels $\varepsilon=1$ and $\varepsilon=0$. If $E$ expands effort $(\varepsilon=1)$, the value of the business is $V(1)$ with probability $p$ and zero otherwise. Since $E$ is financially constrained and does not provide funds, the delay of investments has no economic value to him or her. His or her expected payoff $P(t, \varepsilon)^{E}$ is $P(1, \varepsilon)^{E}=P(0, \varepsilon)^{E}=P(\varepsilon)^{E}$, where $P(1, \varepsilon)^{E}$ specifies the case when the $V C$ invests $K$ in $t=1$, and $P(0, \varepsilon)^{E}$ specifies the case when the $V C$ invests $K$ in $t=0$.

Since the effort of $E$ is essential to the business' success, $E$ 's human capital produces return $\alpha$; $\alpha=0$ if the human capital of $E$ is irrelevant for its success and $\alpha>0$ if it is relevant. $E$ can realise alternative profit $C$ if he or she does not wait for the decision of the $V C$ to expand or abandon the business in $T$. Instead, $E$ employs his or her human capital for alternative use until $T$. For example, $E$ can start working as an adviser and be compensated by the return on his or her human capital. Hence, $C$ describes $E$ 's sunk investment in the business and his or her cost of a risky prospect of capital gain. $\alpha$ is assumed to be a logarithmic return function so that the equation is valid.

$$
C=\alpha T
$$

$E$ maximises

$$
P(\varepsilon)^{E}=\arg \max _{\varepsilon}\left\{s_{E} p V(\varepsilon)-C\right\}
$$

The entrepreneur will choose $\varepsilon=0$ and leave the venture if

$$
\begin{gathered}
C>s_{E} p V(\varepsilon) \\
\frac{C}{s_{E} p V(\varepsilon)}>1
\end{gathered}
$$

In high-risk situations, the $V C$ is in favour of capitalising on the delay option, and a (re-)negotiation of the continuation terms occurs later. Since the entrepreneur's sunk investment $C$ is conditional on the time the entrepreneur spends within the venture before continuation is approved, $E$ is more likely to demand a higher share in the venture should the VC want to delay the expansion. Since $C$ is also a function of $E$ 's return on his or her human capital $\alpha$, compensation is further conditional on the qualification of $E$. Highly qualified $E \mathrm{~s}$ 
thus are more likely to demand a higher share in the venture than are less qualified $E$ s should the VC want to delay the expansion of the venture. E's participation constraint P.C. ${ }^{E}$ is

$$
s_{E} p V(1) \geq C
$$

\subsection{Solution without Relevance of Human Capital}

In the first case, human capital has no relevance. By definition, this is $\alpha=0$. E's benefit $C$ from choosing $\varepsilon=0$ is $C=0$. Inserting this into P.C. ${ }^{E}$, the minimum payoff $P(T)^{E}$ to incentivise $E$ to choose $\varepsilon=1$ is

$$
P(T)^{E^{* *}}=0
$$

$E$ will always stay in the venture. The $V C$ maximises $P(T)^{V C} . T^{* *}$ and $S_{E}^{* *}$ is

$$
\begin{aligned}
& T^{* *}=1 \\
& S_{E}^{* *}=0
\end{aligned}
$$

The payoff to the $V C$ is

$$
P\left(T^{* *}\right)^{V C}=[-\mathrm{K}+V(1)] p
$$

The $V C$ earns the entire payoff from the venture and realises the total value of the delay option. This shows that $E \mathrm{~s}$ without valuable human capital cannot realise a substantial profit in a $V C$-entrepreneur relationship.

\subsection{Solution with Relevance of Human Capital}

In the second case, $E$ owns human capital, and it produces a return. By definition, this is $\alpha>0$. For $T>0, E$ can realise benefit from choosing $\varepsilon=0$ and engaging in an alternative activity, and this benefit goes only to him or her. $V C$ has to vest share $S_{E}$ of the venture's payoff to $E$ to incentivise him or her to stay in the business and to choose $\varepsilon=1$. With respect to the participation constraint of the entrepreneur P.C. ${ }^{E}, S_{E}^{*}$ is

$$
\begin{aligned}
& \text { P.C. } .^{E}: s_{E} p V(1)=\alpha T \\
& S_{E}^{*}=\frac{\alpha T}{p V(1)}
\end{aligned}
$$


The return on the entrepreneur's human capital $\alpha$ and the market risk $(1-p)$ increase share $S_{E}$ vested to the entrepreneur and reduce the residuum share of the $V C$. Now, the timing of the (re-)negotiation is a crucial issue in the share vested to $E$. The $V C$ can reduce share $S_{E}$ vested to the entrepreneur when initiating (renegotiation earlier. For $V(1)=1$, we maximise payoff $P(T)^{V C}$ of the $V C . T^{*}$ is

$$
T^{*}=\frac{(p-1)^{2}}{4 \alpha^{2}}
$$

The payoffs to the $V C$ and $E$ are

$$
\begin{aligned}
& P\left(T^{*}\right)^{V C}=\left(1-S_{E}^{*}\right) p V(1)-K+\theta_{\pi}\left(T^{*}\right)[-K(p-1)] \\
& P(1)^{E}=\alpha T^{*}
\end{aligned}
$$

In this case, the $V C$ and $E$ share the surplus from the business. $E$ earns the return from his or her human capital, and the $V C$ receives the residuum payoff and the value of the delay option.

\subsection{Timing of Follow-on Investments}

For any level of $\alpha$, the $V C$ optimally delays the investment if market risk $(1-p)$ increases because the delay option has a higher value in this situation. With $T>0$, the prospect of capital gain of the entrepreneur becomes riskier because the probability that the $V C$ finally abandons the business is high. For $T>0$, the sunk investments of the entrepreneur rise if the entrepreneur has specific human capital, i.e. if $\alpha>0$. $E$ will renegotiate his or her share in the profit, and the $V C$ has to vest share $S_{E}>0$ to $E$, conditional on delay $T$. For a higher level of $E$ 's human capital, $E$ demands a higher share in the company to compensate for the risk of the venture.

The optimal timing of investments hence derives from the marginal profits of delaying the risky investments and marginal compensation of E. Deriving P.C. ${ }^{E}$ for $t$, it is

$$
\begin{aligned}
& \frac{\partial P(O)^{V C}}{\partial t}+\frac{\partial D(T)}{\partial t} \leq \frac{\partial P(1)^{E}}{\partial t} \\
& \frac{\partial\left(\left[1-\frac{\alpha T}{p V(1)}\right] p V(1)-K+T^{0.5}[-K(p-1)]\right)}{\partial t} \leq \frac{\partial\left(\frac{\alpha T}{p V(1)} p V(1)\right)}{\partial t}
\end{aligned}
$$

For $V(1)=1$, 


$$
\begin{aligned}
& -\alpha-\frac{p-1}{2 \Delta T^{0.5}} \leq \alpha \\
& \Delta T \leq-\left(\frac{p-1}{4 \alpha}\right)^{2}
\end{aligned}
$$

The marginal delay to follow-on investments is negative. The explanation for this is that the marginal value of the delay option decreases over time, whereas the marginal compensation of $E$ for his or her involvement in the risky venture is a linear function. Consequently, it is not optimal to realise the total value of the delay option if $E$ has any specific human capital. The equation shows that the return on the human capital is multiplicative on marginal $T$, as illustrated in Figure 2.

\section{[INSERT FIGURE 2 HERE]}

In the recent literature, it has been demonstrated that the relevance of $E$ 's human capital is related to the extent of staging. We expect a dynamic interaction among human capital, market risk and staging intensity. We summarise the results from the formal model in three empirically testable hypotheses.

H.1. Interaction of human capital and market risk increases staging intensity.

H.2. Controlling for interaction, the impact of human capital on staging intensity decreases.

H.3. Controlling for interaction, the impact of market risk on staging intensity decreases.

Other characteristics such as the experience of the entrepreneur, the exit plans, and the use of control or veto rights might influence the above relationships (Cumming and Johan, 2008). The joint impact of these items on the interdependency between agency risk and market risk is left for future research.

\section{Empirical Approach}

\subsection{Sample}

Our sample covers individual financing rounds from VC-backed entrepreneurial firms based in 15 European countries $^{1}$ for the period from 2003/01/01 to 2015/12/31. Information about the entrepreneurial firm characteristics and the deal characteristics is from Dow Jones VentureSource. Ratios from listed peers are from Compustat Global.

\footnotetext{
${ }^{1}$ Belgium, Austria, France, Germany, Greece, Ireland, Italy, Luxembourg, Netherlands, Portugal, Spain, United Kingdom, Denmark, Finland, Sweden
} 
To identify listed peers, we include all firms that are listed on the major exchange in the 15 European countries considered. Quotations of public market indices are also from Thomson Reuters Datastream. The Global Industry Classification Scheme (GICS) for industry classifications is from MSCI Inc.

We exclude firms from the energy and utilities sector since energy-related infrastructure ventures and renewable energy production were strongly supported and highly regulated by the European Union within the sample period. To further match the formal model's setup to our exclusive focus on equity financing, we keep only observations for which the preceding investment and the follow-on investment are pure equity funding.

\subsection{Methodology}

We test our hypotheses in a natural experiment. We use a difference-in-difference approach to analyse how the timing of the follow-on investment is impacted by increases in the environmental risk and the moral hazard risk of the venture. For this approach, we track the change in the environmental risk in the 365 days before the follow-on investment. We censor observations if no follow-on investment is observed. The censoring date is the date of the initial public offering, the acquisition or the bankruptcy of the firm. Ongoing investments are censored after five years (1,825 days). To follow each event for five years, we restrict our analysis to financing events that occurred between $2003 / 01 / 01$ and $2010 / 12 / 31$. This leaves us with 3,639 observations.

We relate the environmental risk to accumulated market risk, as measured by market price volatility. This is tracked by the Euro Stoxx 50 Volatility Index (VSTOXX). To fit information about the timing into a parametric regression model, we use an event-time model. Event-time models are commonly used in duration studies (Gompers, 1995; Li, 2008). The model fits the paper's focus on the timing of investments, since the estimation parameters can be directly interpreted as the influence of the timing of the follow-on investment. The model is

$$
T_{i, k}=\beta_{0}+\beta_{1} \text { Risk }_{t}+\beta_{2} \text { Asset }_{i}+\beta_{3} \text { Risk }_{t} \text { Asset }_{i}+\beta_{4} X_{i, k}+\sigma \epsilon
$$

where $T_{i, k}$ is the time elapsed between financing round $k$ and follow-on round $k+1$ for firm $i$. Ris $k_{t}$ captures the change in market risk before the follow-on round. It is a dummy variable equal to one if the market risk increased in the 365 days before the follow-on investment and zero otherwise. $\beta_{1}$ estimates the effect of market risk changes on the timing of the follow-on investment. Asset $_{i}$ is a vector of cross-sectional variables that captures firm $i$ 's asset structure to approximate the relevance of the entrepreneur's human capital. $\beta_{2}$ estimates the cross-sectional effect of agency risk on the timing of future investments. $\beta_{3}$ is the differencein-difference estimator. $X_{i, k}$ is a vector of covariates specifying the deal characteristics of financing round $k$ and the firm characteristics of firm $i, \beta_{4}$ is the vector of its estimation parameters. $\epsilon$ is a Weibull distributed error term. The Weibull distribution is reliable in an event-time estimation because it allows for an unknown scaling factor $\sigma$ and for both increasing and decreasing hazard functions. For an increasing hazard function, 
the Weibull distribution approximates to a normal distribution and has exponential and Rayleigh distributions as special cases. Hence, it can be recognised as a more reliable approach in handling event-time data.

\subsection{Measures}

\subsubsection{Relevance of Entrepreneur's Human Capital}

The major asset of ventures is their growth opportunity. The growth opportunity of an entrepreneurial venture primarily emerges from the growth potential and innovativeness of its industry (Brush and Chaganti 1999; Chandler and Hanks 1994; Covin et al. 1990; McDougall et al. 1992). Growth opportunity is an intangible firm asset. For firms with a high fraction of intangible assets, the human capital of the entrepreneur has been found to be a critical determinant of success (Colombo and Grilli 2010; Davila et al. 2003; Shrader and Siegel 2007). Therefore, we can use the firm's asset structure to approximate the relevance of the entrepreneur's human capital. We approximate an entrepreneurial firm's asset structure by the asset structure of listed peers. We approximate the asset structure by the peer's median market-to-book ratio and the intangible-to-total asset ratio. To find an appropriate peer group of listed companies, we match sector classifications provided by Dow Jones VentureSource to the GICS classification scheme used by Compustat Global. Industry structure slightly differs between the GICS classification and the classification by Dow Jones. We match the classification schemes manually based on industry descriptions.

\subsubsection{Control Variables}

VCs are active investors and are deeply involved in the management of the business. They provide entrepreneurs access to their broad network, which helps them, for example, hire staff and find business partners. The VC's effort to support and advise the entrepreneur is an essential factor of the venture's success. Since this is also non-observable and non-contractible from the perspective of the entrepreneur, a double-sided moral hazard problem exists. This problem is discussed in several studies, such as Repullo and Suarez (2004), Schmidt (2003), and Casamatta (2003). A common solution to this problem is the use of convertible securities. Since we restrict our sample to observations with equity funding, a double-sided moral hazard problem may be observed. To control for the extent of this effect, we control for the number of deals that the lead VC executes in the respective sample period as a lead (e.g., Cumming 2006; Pu and Fang 2016). This provides a measure of the VC's interest in the single firm and hence the effort he or she may provide to support his or her portfolio firms.

Furthermore, the VC's effort to support and advise the entrepreneur may be related to the VC's aims. We differentiate between three types of VCs. Financially oriented VCs aim to exit the company within a prespecified investment period to realise a financial return. Strategically oriented VCs, such as corporatesponsored VCs, aim to adjust their old business model to a new technological development and realise a high return from the investment at the corporate level. Differences might be found between domestic or international VCs (Devigne et al. 2016). Publicly sponsored VCs pursue a strategy that promotes entrepreneurial activity in a geographic region through knowledge building or cluster building (Lerner 2002; 
Lerner 2009). Such strategies have been shown to influence investment duration (Cumming and MacIntosh 2001; Cumming and Johan 2010). Hence, the aim of a publicly sponsored VC is highly political but return oriented. Consequently, he or she has a different incentive than do other types of VCs to add value to entrepreneurs. Thus, we control the affiliation of deals with publicly sponsored VCs.

According to the value-added hypotheses by Brander et al. (2002), the syndication of a deal with other VCs improves business performance because more VCs screen investment opportunities more efficiently and offer better managerial support than does a single VC investor. However, free-riding incentives hamper individual VCs' incentive to exert effort in a syndicated deal (Grossman and Hart 1980; Hölmstrom 1982; Pichler and Wilhelm 2001; Wilson 1968). Thus, the positive effect of syndication on the VC-entrepreneur relationship is hampered by confounding effects in the VC-VC relationship. Thus, the venture's total performance suffers from dead-weight loss in large syndicates. We control for the deal's syndication size and the square of the deal's syndication size to account for both effects.

\subsection{Results}

Table 1 provides initial insights about the VC investment policy. In Panel A, we present our variable of interest, the time to the follow-on investment. Further, we present sub-samples clustered by market uncertainty and entrepreneur's human capital. Using all observations, the time to the follow-on investment is 554 days, if market uncertainty is unchanged or decreased prior to the follow-on investment $($ Risk $=0)$. Time to the follow-on investment is 670 days, if market uncertainty increased prior to the follow-on investment $($ Risk $=1)$. Hence, VC's capitalise on delaying investments when markets are uncertain.

We further sub-divide the clusters by high $(I A>\overline{I A} ; M t B>\overline{M t B})$ and low $(I A \leq \overline{I A} ; M t B \leq \overline{M t B})$ relevance of human capital. For high market uncertainty and high relevance of human capital, the time to the followon investment is shorter than time to the follow-on investment in the entire sample. Accordingly, for high market uncertainty and low relevance of human capital, time to the follow-on investment is longer than time to the follow-on investment in the entire sample. This relationship indicates that high relevance of human capital restricts delaying investments. In an uncertain market, the VC earns a higher rent from the delay option for investments in ventures with a low relevance of human capital.

In Panel B, we analyse whether VCs react to a change in the market uncertainty by adjusting their investment and syndication policy. In uncertain markets, VCs invest in fewer businesses, as indicated by a smaller portfolio size ( $P f . S$.). Therefore, they bundle their resources to fewer businesses and increase the value added. This investment policy reduces the double-sided moral hazard problem by incentivising the entrepreneur to simultaneously increase his or her effort. A similar effect is found for syndication. In uncertain markets, VCs join together to larger syndicates, as indicated by larger syndication sizes (Synd.S.). This increases value added by the VCs. The findings indicate that VCs actively monitor the business in order to increase its success rate in high-risk environments through enhanced value added. This also 
reduces the entrepreneur's fear that the VC will abandon the venture in the future, because the sunk investments of the VC increase accordingly.

\section{[INSERT TABLE 1 HERE]}

The staging investment activity of VCs is analysed using the multivariate model. The results are presented in Table 2. Model (1) is the baseline model that includes the control variables. According to previous studies (Gompers 1995), we interpret that an increased staging activity, which is indicated by a decreasing time to the follow-on investment, is related to moral hazard concerns for the VC. Double-sided moral hazard decreases the time to the follow-on investment. Affiliation with publicly sponsored investors increases the time to the follow-on investment, indicating that those investors care less about entrepreneur's moral hazard than return-oriented investors. Finally, moral hazard concerns for the VC decrease in syndicates, however the effect is U-shaped with respect to the size of the syndicate. All effects are stable across the different estimations.

In model (2), we include the variables of interest. The explanatory power of the model increases, as indicated by a lower $A I C$ criterion. The Weibull shape is close to 1 in all estimations, indicating random events. Model (3) tests hypotheses H.1. to H.3. for all observations. Models (4) to (10) present robustness checks for different sub-samples. In model (4), we exclude the years of the financial crisis (2008 and 2009). In model (5), we estimate timing of follow-on investments that follow the first investment round a venture receives. In model (6), we estimate timing of follow-on investments that follow the later than first investment rounds. With this approach, we address the concern raised by Krohmer et al. (2009). They argue that agency risk is present to a greater extent in the early stage of a venture, when uncertainty about entrepreneur's effort and ability is high, whereas market risk is present to a greater extent in the later stage of a venture, when the VC decides whether to exit or write off the business. In models (7) and (8), we estimate the timing of follow-on investments for sub-samples of exited and non-exited firms. Finally, to check for a country bias, model (9) excludes ventures initiated in the United Kingdom from the estimation. Model (10) estimates timing for businesses initiated in the United Kingdom only.

Hypothesis H.1. states that interaction of human capital and market uncertainty increases staging. This is tested by the difference-in-difference estimates. In model (3), the coefficient for Risk $* M t B$ is negative and statistically significant at the $5 \%$ level. The effect stays significant at the $5 \%$ level if we exclude the years of the financial crisis. In models (5) and (6), we find that the effect is significant in later stages of a venture, when the VC decides whether to exit or write off the business. The risk of losing the prospect of capital gain becomes a severe issue in this stage except if the entrepreneur is certain about the quality of the firm and that the VC not going to abandon the business in a high-risk situation. This is seen as interaction of human capital and market risk does not impact the timing of investments for exited firms that describe high quality business models. However, interaction impacts the timing of investments to non-exited firms. Those firms are of minor quality, and the entrepreneur has issue that the VC will abandon the business in a high-risk 
situation. Thus, our findings strongly support the assumption that market risk is driving entrepreneur's moral hazard.

Hypothesis H.2. states that controlling for interaction between the two risks, the impact of human capital on staging decreases. This is a necessary condition to prove that market risk is driving entrepreneur's moral hazard. The coefficient for $M t B$ is insignificant in model (2), and significant at the $1 \%$ level in model (3). The effect of human capital is positive and the difference-in-difference effect is negative. The single effect of human capital cannot be associated with moral hazard risk for the VC, indicating that entrepreneur's moral hazard emerges from market uncertainty. The coefficient for $M t B$ is further significant in models (6) and (8). This is in later stages and non-exited businesses. The insignificant coefficient for $M t B$ and the significant coefficient for the difference-in-difference estimate indicate that moral hazard can be overcome in certain markets. However, uncertain markets allow the entrepreneur to hide the true quality of the business, raising the moral hazard risk for the VC.

Hypothesis H.3. states that, controlling for interaction between the two opposite effects, the impact of market risk on staging intensity decreases. In model (2), VCs delay follow-on investments in uncertain markets on average by $13.6 \%$. This corresponds to 68 days, or approximately 2.5 months. The effect is statistically significant at the $1 \%$ level. Controlling for interaction between human capital and market uncertainty in model (3), Risk delays the follow-on investment on average by $28.9 \%$. This corresponds to 154 days, approximately 5 months. The single effect of market uncertainty is associated with a significant higher value of the delay option. Thus, the value of this option is constrained by the entrepreneur's moral hazard that emerges from market uncertainty. In models (6) and (8), the joint effect of the two risks significantly increases the coefficient for Risk compared to the other models. Hence, the results indicate that the value of the delay option is transferred to qualified entrepreneurs in high-risk situations to keep them engaged in the business when the prospect of capital gain becomes more risky.

\section{[INSERT TABLE 2 HERE]}

\section{Conclusion}

In this paper, we analyse the staging investment policy of VC funds. We model the timing of follow-on investments to expand existing entrepreneurial ventures in a set-up with market risk and agency risk. In this set-up, the VC has the opportunity to delay the follow-on investment in the business to wait for additional informational updates. This is economically valuable if future market conditions are uncertain and if this uncertainty resolves over time (Dixit and Pindyck 1994; McDonald and Siegel 1986; Trigeorgis 1996). However, we argue that capitalising on the delay option creates the wrong incentives for the entrepreneur in high-risk situations. In such situations, the prospect of capital gain from his or her entrepreneurial activity becomes more risky as there is a higher probability that the VC will finally decide to abandon the business. 
This offers some interesting new implications for optimal investing. In particular, we demonstrate that market uncertainty must result in a decreasing marginal delay of the follow-on investment as the entrepreneur's human capital becomes more important for the business. This is because highly qualified entrepreneurs undergo high sunk investments by continuing to provide effort to a business for which expansion is highly uncertain.

Our results demonstrate that a large fraction of moral hazard risk in the VC-entrepreneur relationship stems from environmental risk. Our empirical analysis shows that this relationship is present to a greater extent in the later stage of a venture, when the VC decides whether to exit or write off and for non-exited firms. This underpins our theory of a high-risk profit-sharing situation for the entrepreneur being created by VC's flexibility to abandon the business in an uncertain environment.

Acknowledgements: We acknowledge the DALAHO Hohenheim for the access to their databases. We acknowledge Dow Jones for providing Venture Source, Standard \& Poor's for providing Compustat Global, and Thomson Reuters for providing Datastream. We thank Tereza Tykvová, George Hübner, Christos Koulovatianos, Thomas Bonesire, Milos Vulanovic and the participants of the Academy of Entrepreneurial Finance (Europe) Conference, the World Finance and Banking Symposium at the University of Dubai, the 14th Corporate Finance Day at the KU Leuven, the 4th International PhD Colloquium on Financial Topics during a Time Period of Financial and Monetary Changes at the RWTH Aachen University, the HVB Doctoral Colloquium, the 2nd and 3rd Hohenheim Finance Workshops, and the Research Seminar - Finance \& Law at HEC Liège for their valuable comments.

\section{References}

Amit, Raphael, James Brander, and Christoph Zott. 1998. "Why do Venture Capital Firms Exist? Theory and Canadian Evidence". Journal of Business Venturing 13 (6): 441-466.

Bergemann, Dirk, and Ulrich Hege. 1998. "Venture Capital Financing, Moral Hazard and Learning." Journal of Banking \& Finance 22 (6): 703-735.

Brander, James A., Raphael Amit, and Werner Antweiler. 2002. "Venture-Capital Syndication: Improved Venture Selection vs. The Value-Added Hypothesis." Journal of Economics \& Management Strategy 11 (3): 423-452.

Brush, Candida G., and Radha Chaganti. 1999. "Businesses Without Glamour? An Analysis of Resources on Performance by Size and Age in Small Service and Retail Firms." Journal of Business Venturing 14 (3): 233-257.

Casamatta, Catherine. 2003. "Financing and Advising: Optimal Financial. Contracts with Venture Capitalist." The Journal of Finance 58 (5): 2059-2086.

Chan, Yuk-Shee, Daniel Siegel, and Anjan V. Thakor. 1990. "Learning, Corporate Control and Performance Requirements in Venture Capital Contracts." International Economic Review 31 (2): 365381.

Chandler, Gaylen N., and Steven H. Hanks. 1994. "Founder Competence, the Environment, and Venture Performance." Entrepreneurship Theory and Practice 18 (3): 77-90.

Colombo, Massimo G., and Luca Grilli. 2010. "On Growth Drivers of High-tech Start-ups: Exploring the Role of Founders' Human Capital and Venture Capital." Journal of Business Venturing 25 (6): 610-626. 
Cornelli, Francesca, and Oved Yosha. 2003. "Stage Financing and the Role of Convertible Securities." The Review of Economic Studies 70 (1): 1-32.

Covin, Jeffrey G., Dennis P. Slevin, and Teresa Joyce Covin. 1990. "Content and Performance of GrowthSeeking Strategies: A Comparison of Small Firms in High-and Low-Technology Industries." Journal of Business Venturing 5 (6): 391-412.

Cumming, Douglas. 2006. "The Determinants of Venture Capital Portfolio Size: Empirical Evidence." The Journal of Business 79 (3): 1083-1126.

Cumming, Douglas, and Sofia Johan. 2008. "Preplanned Exit Strategies in Venture Capital." European Economic Review 52 (7): 1209-1241.

Cumming, Douglas, and Sofia Johan. 2010. "Venture Capital Investment Duration." Journal of Small Business Management 48 (2): 228-257.

Cumming, Douglas, and Jeffrey G. MacIntosh. 2001. "Venture Capital Investment Duration in Canada and the United States." Journal of Multinational Financial Management 11 (4-5), 445-463.

Davila, Antonio, George Foster, and Mahendra Gupta. 2003. "Venture-Capital Financing and the Growth of Startup Firms." Journal of Business Venturing 18 (6): 689-708.

Devigne, David, Sophie Manigart, and Mike Wright. 2016. "Escalation of Commitment in Venture Capital Decision Making: Differentiating between Domestic and International Investors." Journal of Business Venturing 31 (3): 253-271.

Dixit, Avinash K., and Robert S. Pindyck. 1994. Investment under Uncertainty. Princeton: Princeton University Press.

Gompers, Paul A. 1995. "Optimal Investment, Monitoring, and the Staging of Venture Capital." The Journal of Finance 50 (5): 1461-1489.

Grossman, Sanford J., and Oliver D. Hart. 1980. "Takeover Bids, The Free-Rider Problem, and the Theory of the Corporation." The Bell Journal of Economics 11 (1): 42-64.

Hölmstrom, Bengt. 1982. "Moral Hazard in Teams." The Bell Journal of Economics 13 (2): 324-340.

Hsu, Yao-Wen. 2010. "Staging of Venture Capital Investment: A Real Options Analysis." Small Business Economics 35 (3): 265-281.

Kirilenko, Andrei A. 2001. "Valuation and Control in Venture Finance." The Journal of Finance 56 (2): 565587.

Krohmer, Philipp, Rainer Lauterbach, and Victor Calanog. 2009. "The Bright and Dark Side of Staging: Investment Performance and the Varying Motivations of Private Equity Firms." Journal of Banking \& Finance 33 (9): 1597-1609.

Lerner, Josh. 2002. "When Bureaucrats Meet Entrepreneurs: The Design of Effective 'Public Venture Capital' Programmes." The Economic Journal 112 (477): F73-F84.

Lerner, Josh. 2009. Boulevard of Broken Dreams: Why Public Efforts to Boost Entrepreneurship and Venture Capital Have Failed--and What to Do About It. Princeton: Princeton University Press.

Li, Yong. 2008. "Duration Analysis of Venture Capital Staging: A Real Options Perspective." Journal of Business Venturing 23 (5): 497-512.

McDonald, Robert, and Daniel Siegel. 1986. "The Value of Waiting to Invest." The Quarterly Journal of Economics 101 (4): 707-727. 
McDougall, Patricia P., Richard B. Robinson Jr., and Angelo S. DeNisi. 1992. "Modeling New Venture Performance: An Analysis of New Venture Strategy, Industry Structure, and Venture Origin." Journal of Business Venturing 7 (4): 267-289.

McGrath, Rita Gunther. 1997. "A Real Options Logic for Initiating Technology Positioning Investments." The Academy of Management Review 22 (4): 974-996.

Neher, Darwin V. 1999. "Staged Financing: An Agency Perspective." The Review of Economic Studies 66 (2): 255-274.

Pichler, Pegaret, and William Wilhelm. 2001. "A Theory of the Syndicate: Form Follows Function." The Journal of Finance 56 (6): 2237-2264.

Pindyck, Robert S. 1993. "Investments of Uncertain Cost." Journal of Financial Economics 34 (1): 53-76.

$\mathrm{Pu}, \mathrm{Yi}$, and Sihai Fang. 2016. "The Optimal Portfolio Size of Venture Capital under Staged Financing."

Procedia Computer Science 91: 85-93.

Repullo, Rafael, and Javier Suarez. 2004. "Venture Capital Finance: A Security Design Approach."

Review of Finance 8 (1): 75-108.

Sahlman, William A. 1990. "The Structure and Governance of Venture-Capital Organizations". Journal of Financial Economics 27 (2), 473-521.

Schmidt, Klaus M. 2003. "Convertible Securities and Venture Capital Finance." The Journal of Finance 58 (3): 1139-1166.

Shrader, Rod, and Donald S. Siegel. 2007. "Assessing the Relationship between Human Capital and Firm Performance: Evidence from Technology-Based New Ventures." Entrepreneurship: Theory and Practice 31 (6): 893-908.

Trigeorgis, Lenos. 1996. Real Options: Managerial Flexibility and Strategy in Resource Allocation. Cambridge: MIT Press.

Wang, Susheng, and Hailan Zhou. 2004. "Staged Financing in Venture Capital: Moral Hazard and Risks." Journal of Corporate Finance 10(1): 131-155

Wilson, Robert. 1968. “The Theory of Syndicates.” Econometrica 36 (1): 119-132. 
Figure 1: Sequence of Events

\begin{tabular}{lll}
\hline & \multicolumn{1}{|c}{} \\
$t_{0} \leq \mathrm{T} \leq t_{1}$ & $t_{1}$ \\
$E$ initiates the venture & $\begin{array}{l}V C \text { expands the } \\
\text { business. } \\
E \text { and provides effort } \varepsilon .\end{array}$ & $\begin{array}{l}\text { Business' value } V(\varepsilon) \\
\text { is realised. }\end{array}$
\end{tabular}

Figure 2: Illustration of Equation (25): Marginal T

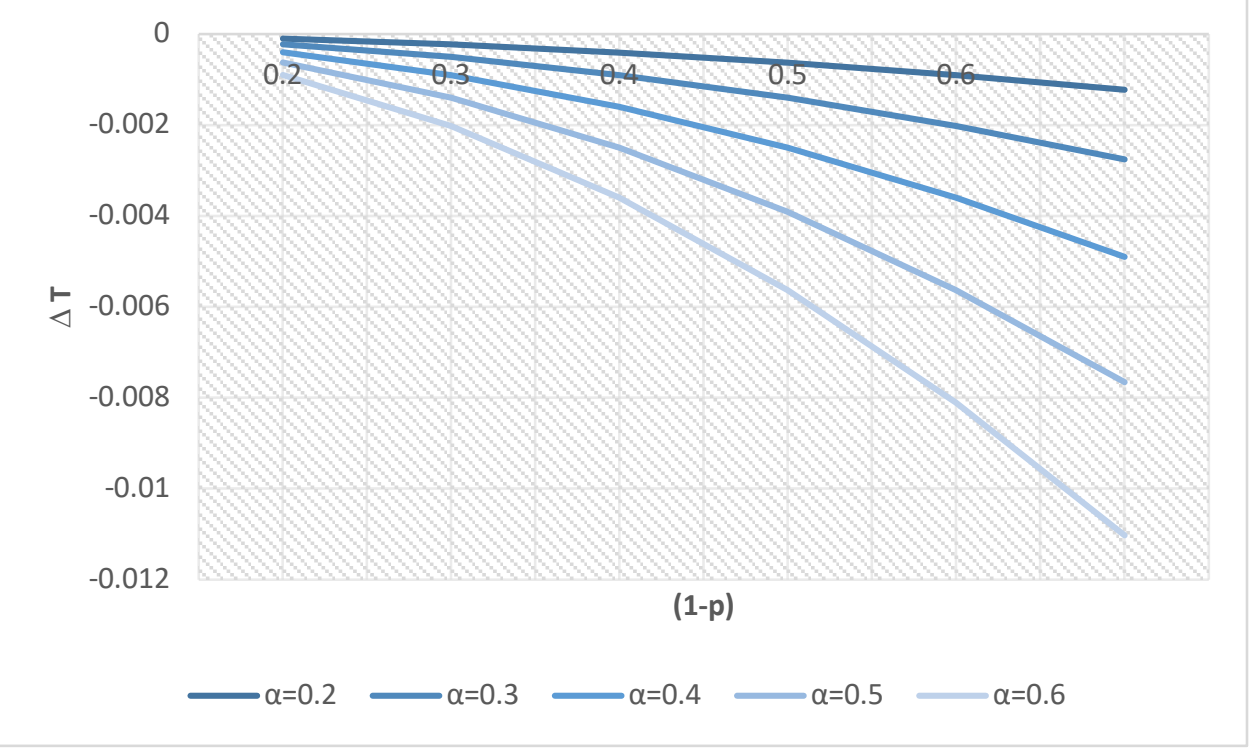


Table 1: Summary Statistics

all $I A>\overline{I A} \quad I A \leq \overline{I A} \quad M t B>\overline{M t B} \quad M t B \leq \overline{M t B}$

\begin{tabular}{|c|c|c|c|c|c|c|}
\hline \multicolumn{7}{|c|}{ Panel A: Average Days to Follow-on Investment } \\
\hline Risk $=0$ & & 554 & 534 & 567 & 563 & 549 \\
\hline Risk $=1$ & & 670 & 662 & 676 & 664 & 676 \\
\hline \multicolumn{7}{|c|}{ Panel B: Means } \\
\hline \multirow{3}{*}{ Risk $=0$} & Pf.S. & 23.17 & 23.89 & 22.73 & 25.11 & 22.08 \\
\hline & PSO & 0.03 & 0.02 & 0.03 & 0.04 & 0.02 \\
\hline & Synd.S. & 2.50 & 2.33 & 2.6 & 2.55 & 2.47 \\
\hline \multirow{3}{*}{ Risk $=1$} & $P f . S$. & 20.17 & 20.73 & 19.8 & 21.42 & 19.28 \\
\hline & PSO & 0.03 & 0.03 & 0.02 & 0.03 & 0.03 \\
\hline & Synd.S. & 2.61 & 2.44 & 2.71 & 2.54 & 2.65 \\
\hline
\end{tabular}

Notes: IA is the intangible asset ratio. $M t B$ is the market-to-book ratio. Pf.S. is the size of the VC's portfolio. PSO is equal to 1 if the lead VC is publicly sponsored and zero otherwise. Synd.S. is the syndication size. 
Table 2: Event-Time Estimation

\begin{tabular}{|c|c|c|c|c|c|c|c|c|c|c|c|c|c|c|c|c|c|c|c|c|}
\hline & (1) & & (2) & & (3) & & (4) & & (5) & & (6) & & (7) & & (8) & & (9) & & (10) & \\
\hline \multirow[t]{2}{*}{ Risk *IA } & & & & & -0.005 & & -0.336 & & 0.424 & & -0.620 & & 1.150 & & -0.244 & & -0.267 & & 0.514 & \\
\hline & & & & & 0.494 & & 0.542 & & 0.658 & & 0.752 & & 1.497 & & 0.526 & & 0.581 & & 0.943 & \\
\hline \multirow[t]{2}{*}{ Risk $* M t B$} & & & & & -0.021 & ++ & -0.018 & + & -0.018 & & -0.023 & + & 0.010 & & -0.027 & ++ & -0.022 & + & -0.019 & \\
\hline & & & & & 0.010 & & 0.011 & & 0.014 & & 0.014 & & 0.022 & & 0.011 & & 0.011 & & 0.020 & \\
\hline \multirow[t]{2}{*}{$I A$} & & & -0.720 & +++ & -0.676 & ++ & -0.782 & ++ & -1.125 & +++ & -0.040 & & 1.632 & & -0.904 & +++ & -0.782 & ++ & -0.256 & \\
\hline & & & 0.241 & & 0.306 & & 0.312 & & 0.405 & & 0.469 & & 1.089 & & 0.321 & & 0.360 & & 0.577 & \\
\hline \multirow[t]{2}{*}{$M t B$} & & & 0.008 & & 0.019 & +++ & 0.021 & +++ & 0.017 & & 0.019 & + & 0.016 & & 0.022 & +++ & 0.021 & ++ & 0.010 & \\
\hline & & & 0.005 & & 0.007 & & 0.008 & & 0.011 & & 0.010 & & 0.016 & & 0.008 & & 0.009 & & 0.014 & \\
\hline \multirow[t]{2}{*}{ Risk } & & & 0.128 & +++ & 0.254 & +++ & 0.225 & ++ & 0.249 & ++ & 0.265 & ++ & -0.167 & & 0.323 & +++ & 0.259 & +++ & 0.260 & + \\
\hline & & & 0.034 & & 0.081 & & 0.088 & & 0.115 & & 0.116 & & 0.198 & & 0.088 & & 0.098 & & 0.147 & \\
\hline \multirow[t]{2}{*}{ LOG (Pf.S.) } & -0.333 & +++ & -0.340 & +++ & -0.340 & +++ & -0.334 & +++ & -0.376 & +++ & -0.300 & +++ & -0.277 & +++ & -0.345 & +++ & -0.370 & +++ & -0.251 & +++ \\
\hline & 0.015 & & 0.018 & & 0.018 & & 0.020 & & 0.026 & & 0.027 & & 0.045 & & 0.020 & & 0.021 & & 0.035 & \\
\hline \multirow[t]{2}{*}{ PSO } & 0.280 & +++ & 0.236 & ++ & 0.230 & ++ & 0.252 & ++ & 0.376 & ++ & 0.067 & & 0.078 & & 0.240 & ++ & 0.245 & ++ & 0.166 & \\
\hline & 0.092 & & 0.104 & & 0.104 & & 0.119 & & 0.148 & & 0.145 & & 0.251 & & 0.113 & & 0.113 & & 0.254 & \\
\hline \multirow[t]{2}{*}{ LOG(Synd.S.) } & 0.153 & +++ & 0.186 & +++ & 0.188 & +++ & 0.224 & +++ & 0.248 & ++ & 0.147 & + & 0.189 & & 0.203 & +++ & 0.235 & +++ & 0.077 & \\
\hline & 0.053 & & 0.062 & & 0.062 & & 0.068 & & 0.112 & & 0.081 & & 0.149 & & 0.068 & & 0.075 & & 0.111 & \\
\hline \multirow[t]{2}{*}{ LOG $(\text { Synd.S. })^{2}$} & -0.062 & ++ & -0.085 & +++ & -0.086 & +++ & -0.097 & +++ & -0.119 & + & -0.068 & ++ & -0.092 & & -0.088 & +++ & -0.107 & +++ & -0.036 & \\
\hline & 0.025 & & 0.029 & & 0.029 & & 0.031 & & 0.064 & & 0.035 & & 0.069 & & 0.031 & & 0.035 & & 0.051 & \\
\hline \multirow[t]{2}{*}{ const. } & 7.200 & +++ & 7.202 & +++ & 7.130 & +++ & 7.083 & +++ & 7.245 & +++ & 6.991 & +++ & 6.717 & +++ & 7.161 & +++ & 7.220 & +++ & 6.863 & +++ \\
\hline & 0.046 & & 0.069 & & 0.079 & & 0.085 & & 0.111 & & 0.116 & & 0.193 & & 0.087 & & 0.093 & & 0.151 & \\
\hline$N$ & 5101 & & 3639 & & 3639 & & 3092 & & 1670 & & 1969 & & 579 & & 3060 & & 2585 & & 1054 & \\
\hline Weibull Shape & 0.973 & & 0.977 & & 0.978 & & 0.975 & & 0.987 & & 0.973 & & 1.074 & & 0.969 & & 0.981 & & 0.977 & \\
\hline$A I C$ & 16061 & & 11436 & & 11435 & & 9713 & & 5244 & & 6198 & & 8367 & & 9682 & & 8134 & & 3308 & \\
\hline
\end{tabular}

Notes: Event time model with Weibull distributed error term. IA is the intangible asset ratio. $M t B$ is the market-to-book ratio. Risk is equal to 1 if risk increased in the 365 days preceding the follow-on investment, and zero otherwise. $P f . S$. is the size of the VC's portfolio. PSO is equal to 1 if the lead-VC is publicly sponsored and zero otherwise. Synd.S. is the syndication size. +++ indicates significance at the $1 \%$ level, ++ indicates significance at the $5 \%$ level, and + indicates significance at the $10 \%$ leve 
